\title{
Research Paper: The Epidemiology of Human Mortality in West Azerbaijan Province, Iran, 2016
}

\author{
Flora Farivarnia $^{1}$ (D), Rasool Entezarmahdi ${ }^{2}$ (D), Mohammad Delirrad ${ }^{\text {3* }}$ (D) \\ 1. Faculty of Medicine, Urmia University of Medical Sciences, Urmia, Iran. \\ 2. Department of Biostatistics and Epidemiology, Faculty of Medicine, Urmia University of Medical Sciences, Urmia, Iran. \\ 3. Department of Forensic Medicine and Toxicology, Faculty of Medicine, Urmia University of Medical Sciences, Urmia, Iran
}

\begin{tabular}{|l|l|}
$\begin{array}{l}\text { Use your device to scan } \\
\text { and read the article online }\end{array}$ & $\begin{array}{l}\text { Irtation: Farivarnia F, Entezarmahdi R, Delirrad M. The Epidemiology of Human Mortality in West Azerbaijan Province, } \\
\text { ijmtfm.v10i4.30049 }\end{array}$ \\
dol'https://doi.org/10.32598/ijmttm.v10i4.30049
\end{tabular}

\section{(i) (5)}

Article info:

Received: 20 Apr 2020

First Revision: 27 Apr 2020

Accepted: 29 May 2020

Published: 12 Dec 2021

\section{Keywords:}

Mortality, Causes of death, Vital statistics, Epidemiology, Iran

\section{ABSTRACT}

Background: This article presents the most recent mortality data in West Azerbaijan Province (WAP) of Iran in 2016 based on selected characteristics, including age, sex, state of residence, and cause of death.

Methods: After the local Ethics Committee approval, we obtained the data for this systematic database study from the local health registration office. The causes of death are processed following the International Classification of Diseases, tenth revision (ICD-10). The vital statistics were refined from the yearbooks of the National Organization for Civil Registration.

Results: In 2016, a total of 14688 deaths were registered in the Health Death Registration System (HDRS) and 14622 in the Civil Death Registration System (CDRS) of WAP ( $\sim \%$ of Iran's mortality). The Crude Mortality Rate (CMR) was 4.30 per 1000, showing an increase of $7.5 \%$ from the 2011 rate. Of the deceased, $56.9 \%$ were males, and $60 \%$ were attributed to urban areas. On average, men died 4 years earlier than women ( 61.2 vs 65.3 years, respectively). The major causes of death in 2016 remained the same as in 2011.

Conclusion: The pattern of human mortality in WAP is comparatively consistent with the other regions of Iran except for the higher rate of neoplasms (19.6\% compared to $10.7 \%$ of the country average) and the lower ratio of certain infectious and parasitic diseases ( $1 \%$ compared to $3.8 \%$ of the national average). There was a significant difference in registering the state of residence between HDRS and CDRS, which is highly recommended for further investigation in future studies.

\section{Introduction}

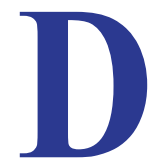

eath is a clear and unavoidable event that can be a mirror for the overall health and disease status of a particular society [1]. Due to its explicit nature, death has a high potential for quantification and specific importance in statistical calculations of any health system as well [2]. Unlike other demographic phenomena, death affects all members of society. It is the only phenomenon that governments cannot focus on to decrease or increase the mortality rates at different times [3]. Most communities

* Corresponding Author:

Mohammad Delirrad, PhD.

Address: Department of Forensic Medicine and Toxicology, Faculty of Medicine, Urmia University of Medical Sciences, Urmia, Iran.

Tel: +98 (44) 33444591

E-mail:delirrad@yahoo.com 
attempt to reduce death and, in parallel, to extend human life $[3,4]$. Despite the importance of mortality studies in public health decision making and determining health priorities, only a few of the most developed countries can issue mortality information with acceptable accuracy and quality [2]. According to the reports of various international organizations, in recent years, although death registration coverage in Iran has improved significantly, still the quality of determining causes of death in death certificates is not acceptable [4].

There are two primary sources for issuing mortality information in Iran. The first one is the Health Death Registration System (HDRS) of the Ministry of Health and Medical Education (MoHME), and the second one is the Civil Death Registration System (CDRS) of the National Organization for Civil Registration (NOfCR). The former is responsible for designing, publishing, and distributing death certificates among physicians throughout the country according to recommendations of the World Health Organization (WHO). Meanwhile, it has developed HDRS since 1997 and registered mortality data by gender, sex, cause of death, time and place of death, inhabitant place of the deceased person, and issued certificates of death by physicians [2-4]. The latter was established in 1918 and is legally responsible for recording four critical events: birth, marriage, divorce, and death. The organization collects death certificates and registers mortality data separately. This organization has also been publishing statistical yearbooks regularly since $2005[3,4]$.

The data obtained from population and housing censuses also have an essential role in estimating and predicting demographic factors such as death [4]. Furthermore, the Legal Medicine Organization is responsible for the publication of the statistics of unnatural and violent deaths [4].

The image of the Iran map on the world map resembles a cat, and West Azerbaijan Province (WAP) is located on the northwest of the map. The Province is one of the 31 Provinces of the country sharing the same borders with Turkey, Iraq, and Azerbaijan's Nakhchivan Autonomous Republic. Also, it neighbors the Provinces of East Azerbaijan, Zanjan, and Kurdistan. Urmia, the capital of the Province, is the largest county in the Province. There are also 16 other counties in the area [5]. According to the latest national census (2016), the population of WAP and Urmia were 3265219 and 1040565 , respectively [6].

Majidi et al. (2016) studied the epidemiology of human mortality in WAP in 2011 and reported 12440 registered deaths in HDRS, which had low coverage (78\%) than the ones in CDRS. Of the deceased, their Mean \pm SD of age was $60.48 \pm 27.08$ (range: 0 -116) years, $56.6 \%$ were males, and $55.6 \%$ belonged to urban areas, with a Crude Mortality Rate (CMR) of 4.04 in 1000 . They concluded that under-reporting or not registered deaths were a problem for many Provinces and regions of the country, such as WAP [4].

According to the law, the general population and housing censuses are conducted every 5 years in Iran. The last census was held in 2016, and its results were published [6]. In the current study, we provide a more accurate picture of the epidemiologic status of mortality rate in WAP by the inclusion of the whole available data, statistics, and information and discussing the strengths and weaknesses of the current death registration systems.

\section{Materials and Methods}

In this systematic database study, we collected the data of HDRS of WAP from the Deputy of Health, Urmia Medical Sciences University, in descriptive tabulations as an MS-Excel spreadsheet. Each record of this file contained the fields related to identity (gender, age), state of residence (Province, city), death location, time of death, and cause of death. After that, the file was stratified according to the age variable. Then, the three-character (original) codes of the cause of death and the blocks of fatalities were refined using the International Classification of Diseases, $10^{\text {th }}$ revision (ICD-10:2008) [7]. Next, they were carefully matched to the data in the file. Additionally, some national and provincial statistics of 2016 were downloaded from NOfCR's website and reviewed carefully $[8,9]$. This study was conducted in a period of an Iranian solar year (1395) equivalent to March 1, 2016, and March 1, 2017 [leap year]. For convenience, the year 2016 is used instead of the Iranian year throughout the text.

The Ethics Committee of Deputy of Research and Technology, UMSU, Urmia, Iran, approved this study's protocol. We reported the final results without specifying the deceased's identities or the physicians issuing the death certificates and burial permissions. Investigators were committed to all principles of ethics in research throughout the study. The Collected data were analyzed using MS-Excel (Microsoft ${ }^{\circledR}$ Excel $^{\circledR}$ 2013, Microsoft Corporation) and SPSS (SPSS for Windows, v. 16.0. 2007, Chicago, SPSS Inc.). We expressed quantitative data as Mean \pm SD. Also, we used frequency and percentage for qualitative data. 


\section{Results}

In this study, 14688 deaths were recorded in HDRS of WAP in 2016. Excluding stillbirth cases ( $\mathrm{n}=633$ ), the total number of deaths registered in the HDRS ( $n=14055)$ was slightly higher than the recent deaths recorded in the provincial CDRS ( $\mathrm{n}=13803$ ), which represents a $101.8 \%$ coverage. There were fatalities throughout the year, with an average of 38 deaths per day in the Province.

More than $95.2 \%(n=13914)$ of the provincial deaths were registered within the legal deadline (10 days after the time of death) at the local offices of NOfCR. The delayed death registrations (arrears) were less than 5\%.

In 9 stillbirth cases and 1 neonate, the gender was not specified. Of remaining, $56.9 \%$ were males $(\mathrm{n}=8000)$ and
$43.1 \%(\mathrm{n}=6054)$ females. The gender ratio of death is defined as the number of dead males to every 100 dead females. In 2016, this ratio was 132 for the whole Province.

The Mean \pm SD of age was $62.9 \pm 12.1$ (range: 0 -119) years for all deceased population; $61.2 \pm 26.0$ (range: 0 -119) years for men; and $65.3 \pm 26.2$ (range: $0-117$ ) years for women. The age pyramid of the deceased by gender in WAP in 2016 is shown in Figure 2. As illustrated, most deaths occurred in people over 50 years of age, with the highest death rate in the ninth decade.

Table 1 summarizes the CMR of the country and WAP in 2016 by gender. As is shown, the CMR of the Province was slightly lower than that in the country. There were also significant discrepancies regarding CMR by

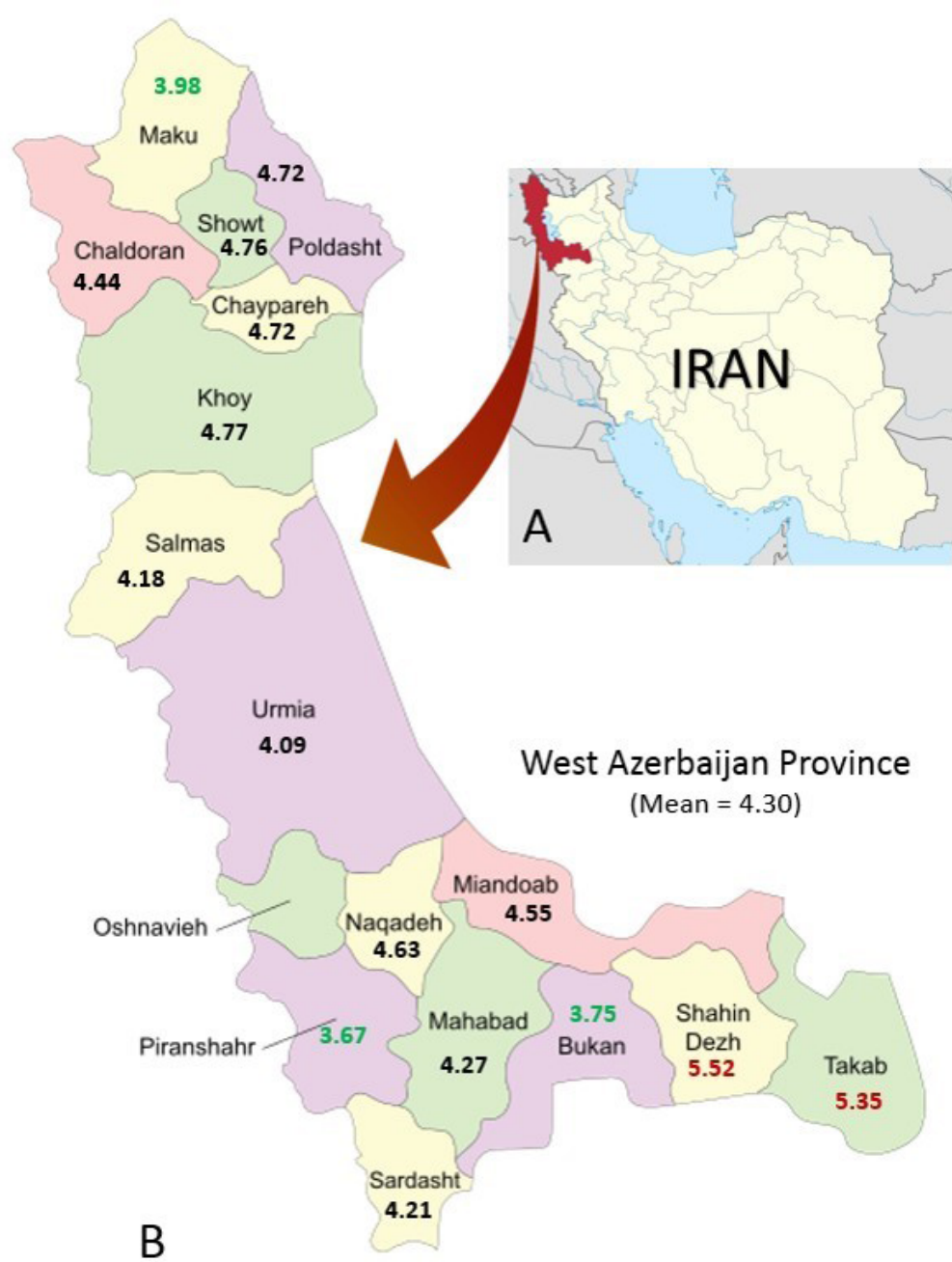
International Journal of
Medical Toxicology \& forensic Medicine Figure 1. A) West Azerbaijan Province in Iran (Coordinates: $\left.37.5528^{\circ} \mathrm{N} 45.0759^{\circ} \mathrm{E}\right)$; B) the Crude Mortality Rate (CMR) (per 1000 population) of each county of the Province in 2016 (Death number=14055, WAP population=3,265,219)

The map without statistics retrieved from Wikipedia contributors [4]. 


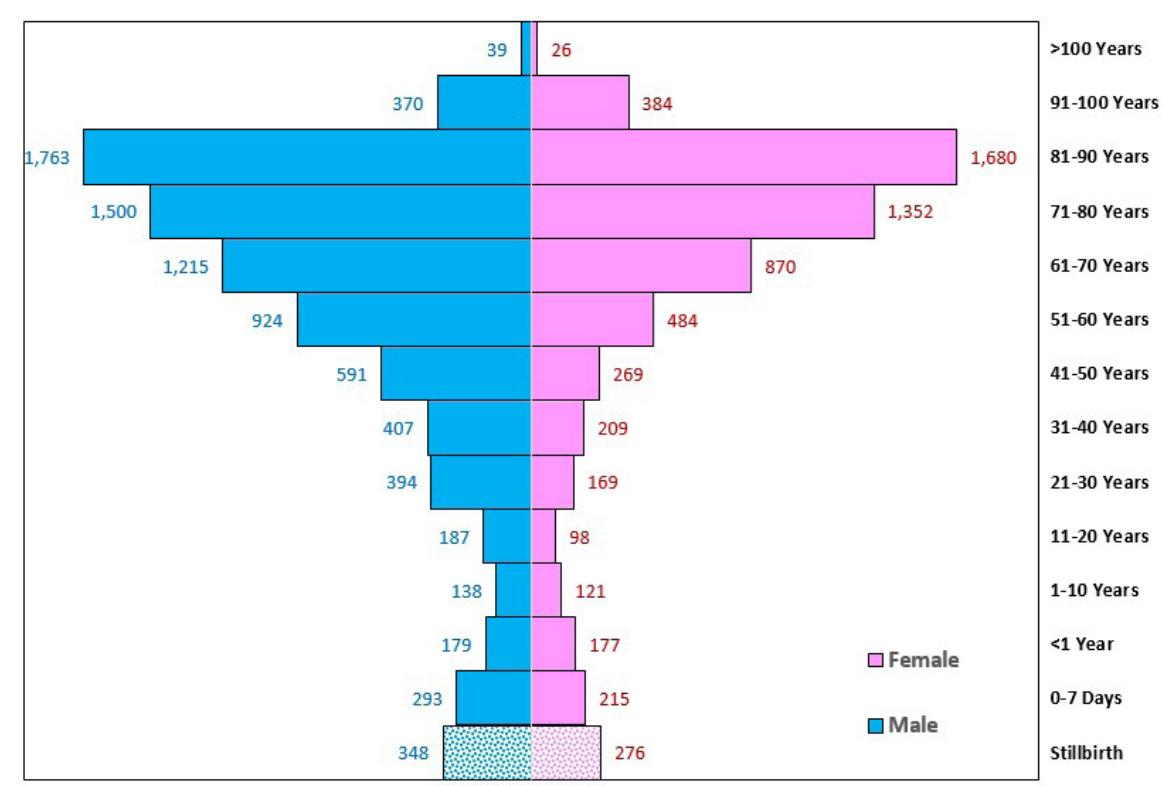

Figure 2. Age pyramid of human deaths by gender in West Azerbaijan Province of Iran (2016) $\quad \begin{aligned} & \text { International Journal of } \\ & \text { Medical Toxicology \& Forensic Medicine }\end{aligned}$

gender among urban and rural areas between HDRS and CDRS.

According to HDRS data, $60 \%(n=8435)$ of the deceased lived in urban areas, and $37.5 \%(\mathrm{n}=5270)$ in rural areas, and the residential status for $2.5 \%(n=350)$ was not clear. The highest and lowest mortality rates in urban areas belonged to the cities of Naqadeh $(\sim 74 \%)$ and Poldasht $(\sim 33 \%)$, respectively. The gender ratios of deaths were 130 and 135 for urban and rural areas of the Province, respectively. On the other hand, CDRS reported $68 \%$ of deaths in urban areas and $32 \%$ in rural areas, and the gender ratios of deaths were reported as 126 for the entire Province, 128 for urban, and 123 for rural areas. These ratios were 129 for the whole country, 132 for the urban area, and 122 for rural areas of Iran in 2016. More importantly, the gender ratio was over 200 in the age group of 15 to 54 years. In other words, the probability of death for men in this age group was twice as much as that for women. We calculated this ratio for the WAP as 213 in 2016 based on HDRS's data.

The geographical distribution of deaths in different counties of WAP during 2016 is illustrated in Figure 1. As can be seen, the mean CRM for the Province was 4.30 in 1000 population in 2016. The CRMs of different counties were variable, and the lowest (3.67 in 1000) and highest (5.52 in 1000) rates were related to Piranshahr and Shahin-Dezh, respectively.

The neonatal mortality rate is obtained by dividing the annual number of neonatal deaths (0-28 days) in a given

Table 1. The Crude Mortality Rate (CMR) of Iran and West Azerbaijan Province in 2016

\begin{tabular}{cccc}
\hline \multirow{2}{*}{$\begin{array}{c}\text { Crude Mortality Rate (CMR)1 } \\
\text { (per 1000 population) }\end{array}$} & \multicolumn{2}{c}{ West Azerbaijan Province } & Iran* \\
\cline { 2 - 4 } Male & HDRS1 & CDRS2* & 5.13 \\
\hline Female & 4.82 & 4.92 & 4.10 \\
\hline Urban areas & 3.77 & 4.02 & 4.65 \\
\hline Rural areas & 3.95 & 4.66 & 4.57 \\
\hline Total population & 4.67 & 4.14 & 4.63 \\
\hline
\end{tabular}

HDRS: Health/Death Registration System, CDCivil Death Registration System,

International Journalof

*Calculated based on data extracted from the National Organization for Civil Registration website [9]. 


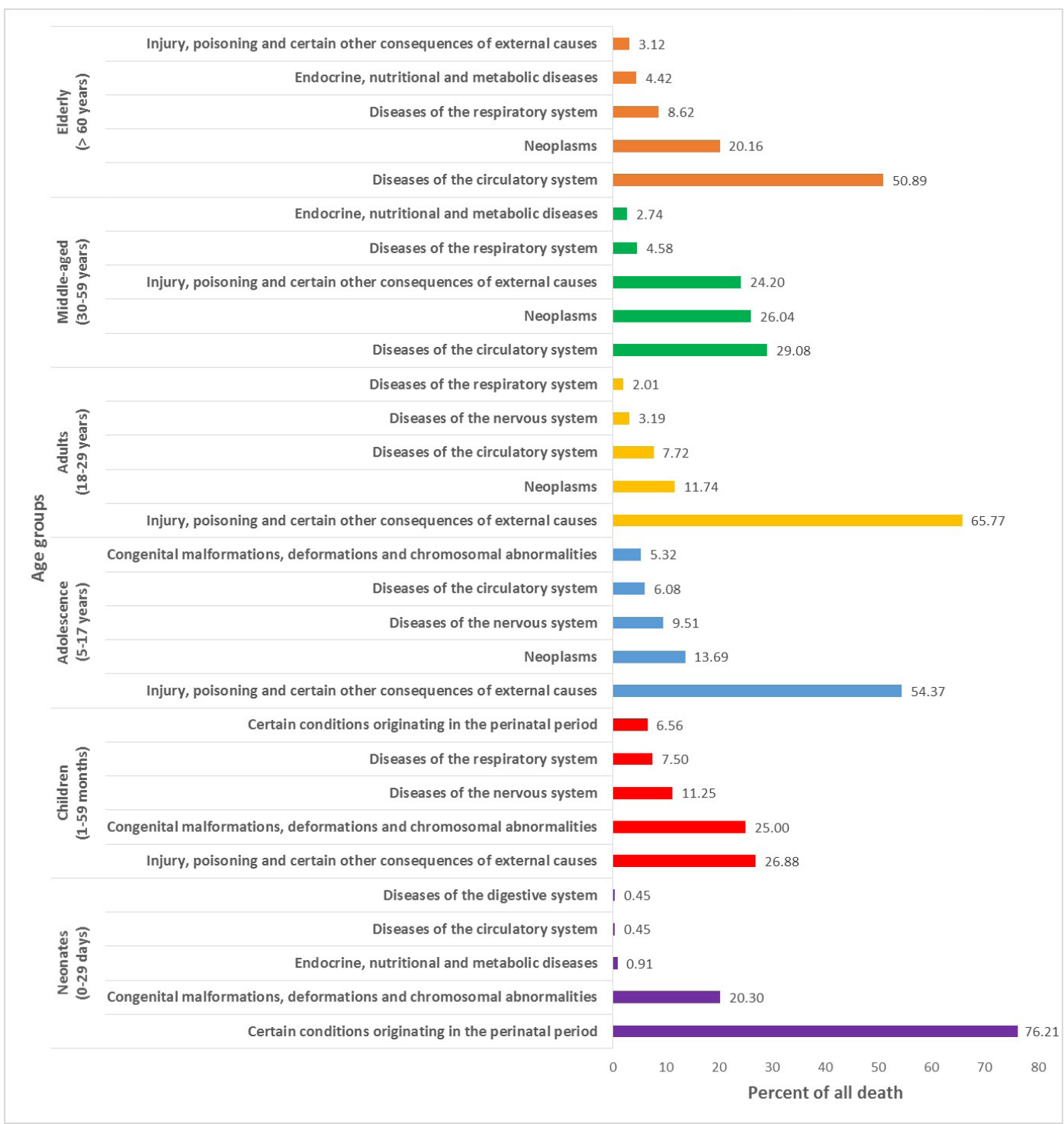

International Journal of

Medical Toxicology \& Forensic Medicin

Figure 3. Top 5 causes of fatalities among different age groups in West Azerbaijan Province of Iran in 2016

population by the number of live births in the same community and is expressed by a factor of 1000 . Our examined data were classified age groups as 0-7 days and above seven days. Therefore, it was not feasible for us to calculate the neonatal mortality rate precisely. Instead, a mortality rate of 0-7 days neonates was estimated at 7.8 per 1000 births in WAP. The rates were 8.6 and 6.8 for male and female infants, respectively.

In the same way, the mortality rate of children under the age of 5 years is calculated by dividing the annual number of under 5-year deaths (excluding $0-7$ days infants) in a given population by the number of live births in the same year, and it is expressed by a factor of 1000 . In the year 2016, the mortality rates of children under the age of 5 years were calculated as 7.8 per 1000 live births, 7.7 for boys, and 7.9 for girls in WAP.
The place of death was not recorded for stillbirths and neonatal deaths. Also, in 116 instances of above seven days, the place of death was not recorded, and for the other 99 cases, it was unknown. For reminders $(n=13332)$, the place of death in a decreasing order were home $(n=6387,47.9 \%)$, hospitals or medical centers $(\mathrm{n}=5535,41.5 \%)$, others $(\mathrm{n}=1070,8.0 \%)$, passages and public places $(n=279,2.1 \%)$, and the sanatoriums $(n=61$, $0.5 \%$ ).

Figure 3 illustrates 5 leading causes of death in different age groups in WAP in 2016. Figure 4 shows the distribution of deaths due to external causes of morbidity and mortality in the Province in the same year. 


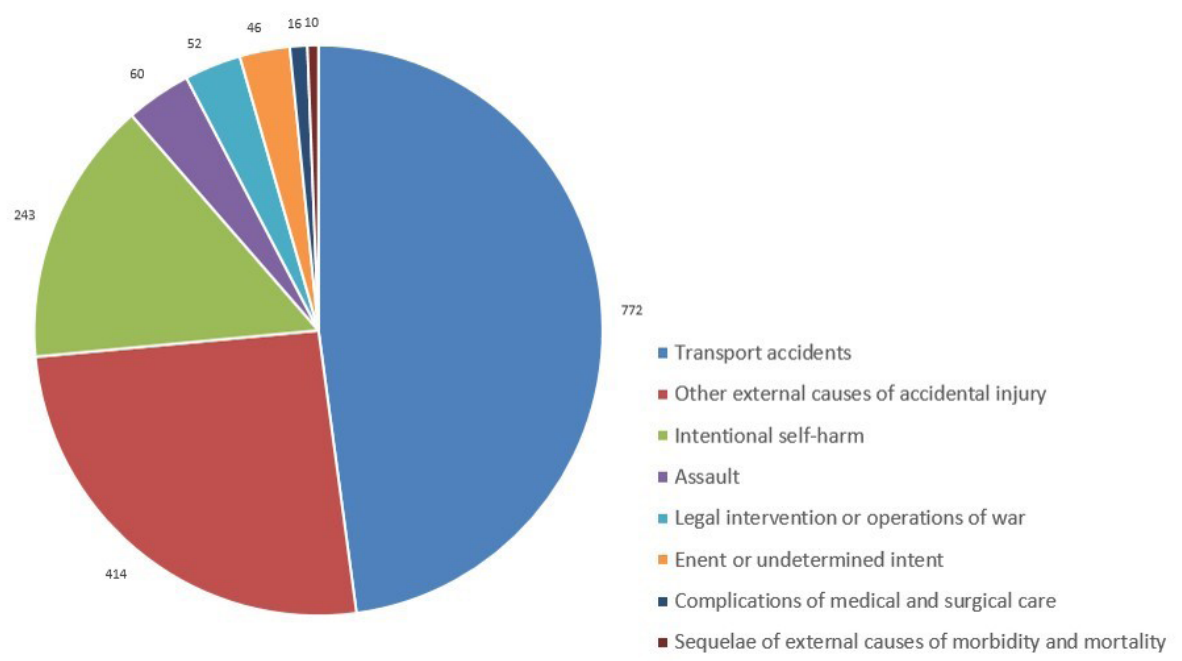

International Journal of
Medical Toxicology \& forensic Medicine Figure 4. Distribution of deaths due to external causes of morbidity and mortality in West Azerbaijan Province of Iran in 2016

\section{Discussion}

In this study, we explored the epidemiology of human mortality in West Azerbaijan Province of Iran during one year (2016). Also, we compared the death information produced by two separate death registration systems (HDRS and CDRS).

According to the general population census of 2016, WAP contained $4.1 \%$ of the country's population [6]. In the same year, $4.4 \%$ of births and about $4 \%$ of the country's deaths belonged to WAP $[8,9]$.

A comparison of the current results with the previous study carried out by Majidi et al. [4] revealed that the population of WAP has increased by about $6 \%$ during 5 years and reached from 3080576 in 2011 to 3265219 in $2016[6,11]$. The total registered numbers of deaths by CDRS were 15929 in 2011 [12] and 14622 in 2016 [9] (a negative growth of $8 \%$ ). However, the total deaths (including stillbirths) registered by HDRS increased from 12440 in 2011 [4] to 14688 in 2016 (a positive growth of $18 \%$ ). This relatively significant difference could be attributed to some reasons. The first one was improving HDRS's coverage, which increased from $78.1 \%$ in 2011 [4] to $102.1 \%$ in 2016. Re-examination of the 2011 census results [11] with the elimination of stillbirths and the retrospective extraction of the current death statistics from 2011 [12] showed that $85.7 \%$ of the ongoing deaths of CDRS in 2011 were recorded in HDRS [4]. Therefore, over the past 5 years, the coverage of death registration by HDRS has mainly improved, and the statistics of both systems have become more coherent with each other. The second reason was improving the current death registra- tion by CDRS, which increased from $87 \%$ in 2011 [12] to $94.4 \%$ in 2016 [9]. Given the 10-day legal deadline for registering a death, the performance of CDRS has also improved significantly during the past 5 years.

The calculated CRMs for WAP in 2016 based on HDRS and CDRS were 4.3 and 4.5 , respectively. In the same year, the CMR of Iran was 4.63. These values were 4.0, 4.9, and 5.17, respectively, for 2011 [4, 12]. However, these numbers do not precisely show whether the Province is getting better or worse in terms of mortality. Therefore, we tried to calculate the proportion of provincial mortality with respect to the country. Thus, by dividing the Province's deaths by the total number of country's deaths in the CDRS, it was found that in 2011, about 3.77\% (15929 out of 422133) [12] and in 2016 about $3.95 \%$ (14622 out of 369751) [9] of the total number of registered deaths in the country occurred in WAP. Considering the population of WAP $(4.1 \%$ of Iran's population in 2016) [6], it seems that the statistics of 2016 is more acceptable. In the same year, CRM for some other Provinces was 5.6 for East Azerbaijan, 4.5 for Kurdistan, and 4.1 for Tehran [9]. Considering the trends of deaths in the world over the last two centuries, we can observe a dramatic decline across the globe during the previous two centuries. Iran is no exception, and the country's CMR has declined from 32.8 in 1921 to 5.8 in 2006 [13-17], 5.17 in 2011 [4], and 4.63 in 2016 [9].

According to our calculation, the mortality rate of children under the age of 5 was 7.8 per 1000 live births in WAP in 2016, which was less than the figure reported in the statistical yearbook (2016) of UMSU (15.3 per 1000 live births) in the same year [10]. We noticed that our 
estimate was for the whole population while the health deputy calculated it only for the Province's rural areas annually. Based on vital events statistics of NOfCR in the same year, we counted these rates to be 9.2 and 11.2 per 1000 live births in WAP and Iran, respectively [8, 9]. A similar status was right about the neonatal mortality rate. We calculated it as 7.8 per 1000 births in 2016 for the entire WAP, while the statistical yearbook (2016) of UMSU reported it as 8.2 per 1000 live births only for rural areas [10].

The gender ratio of mortalities increased from 130 in 2011 to 132 in 2016 in WAP [4, 9, 12]. In other words, the proportion of men's deaths increased slightly compared to women's. In all age groups and most causes of death, men died more frequently than women (except for cervical or breast cancers). This ratio was particularly significant in the case of accidents (336). To be precise, men are approximately 3.5 times more likely to die from trauma or traffic accidents than women. Men are also more likely to die due to "cancers and tumors," "respiratory tract diseases," "hematologic and immune disorders," and "mental and behavioral diseases." By contrast, death due to "endocrine, nutritional and metabolic diseases," "musculoskeletal system and connective tissue diseases," and "skin and subcutaneous tissue diseases" were more common in women. Furthermore, death due to "complications of pregnancy, childbirth, and postpartum" is specific to women. Numerous studies have also reported similar results in different Provinces $[1,3,4,13-16]$.

Additionally, another result was a significant difference in estimating the gender ratio of deaths in WAP between HDRS and CDRS, especially between urban and rural areas. Further analyses suggested that wrongly attributing inhabitant places of the deceased individuals as urban or rural may be the origin of this inconsistency. A re-examination revealed that CDRS recognized $68 \%$ of the deceased as urban and $32 \%$ as rural [10], while in HDRS, $60 \%$ were urban, $37.5 \%$ rural, and $2.5 \%$ unspecified. We did not find the exact cause of this discrepancy in data recording, and it is unclear which data are more accurate. Still, such a variation could also disturb other vital statistics of the Province and even the country, so it is suggested that further studies be undertaken in this regard.

The leading causes of death of WAP in our study were diseases of the circulatory system, neoplasms, and external causes of morbidity and mortality. In 2011, the three common causes of death in the Province were reported as cardiovascular diseases, cancers, and lung diseases, and traffic accidents placed in the fourth rank [4]. This difference was due to the separation of accidents into two categories of traffic accidents and casual accidents in that study. Considering this, the top etiologies of death in the Province have not changed during the past 5 years. Almost similar patterns have been reported from some other regions of Iran [13-16]. The significant causes of death in our Province are substantially identical to the whole country, except for the highest death rate due to neoplasms in the country $(19.6 \%$ compared to $10.7 \%$ nationwide) and a lower rate of specific infectious and parasitic diseases ( $1 \%$ of the Province vs $3.8 \%$ national average) [18].

Physicians are the primary reporters of mortality data in Iran by issuing death certificates and burial permission [18]. To keep up and be informed, many educational courses and workshops have been held for physicians around the country. However, the practice of most doctors in determining causes of death is not appropriate. According to statistics, about $40 \%$ of deaths in WAP occurred in hospitals and medical centers. This figure was $44.6 \%$ in 2011 [4]. Therefore, in the coming years, Urmia University of Medical Sciences and the Ministry of Health and Medical Education should pay more attention to the quality improvement of death certificates. Notably, training of physicians working in hospitals such as medical students, residents, and attending physicians could have a significant impact on improving the quality of determining the cause of death. Moreover, with the release of ICD-11 on June 18, 2018, by WHO (18 years after the introduction and deployment of ICD-10), which has 55000 codes (compared to 14400 codes of ICD-10), and is expected to be adopted by member states by the beginning of 2022 [19], the significance of teaching how to use and apply these codes to death certificates will become more critical.

However, our study had some limitations. In the file obtained from Deputy for Health, some data, such as the exact age of the infants (in days), was not clear to calculate infant mortality rate under 28 days. Also, the identification of physicians issuing death certificates was not mentioned. Such data appear to be recorded in the HDRS, so it is suggested that researchers in future studies also obtain these data.

The study results showed that death rates in WAP were more or less similar to other regions of Iran in 2016, except for the higher rate of neoplasms (19.6\% compared to $10.7 \%$ of the national average) and a lower rate of death due to infectious and specific parasitic diseases ( $1 \%$ compared to $3.8 \%$ of nationwide). We found sta- 
tistical differences about registering the residence of the deceased individuals between two death registration systems (HDRS and CDRS) of the Province, which is suggested to be investigated in future research.

\section{Ethical Considerations}

\section{Compliance with ethical guidelines}

The protocol for this study was approved as a research project by the Ethics Committee of Research, Urmia University of Medical Sciences (IR.umsu.rec.1396.228).

\section{Funding}

This research did not receive any grant from funding agencies in the public, commercial, or non-profit sectors.

\section{Author's contributions}

Conceptualization and Supervision: Mohammad Delirrad; Literature review, Data collection, and Data analysis: Flora Farivarnia; Writing - original draft, Mohammad Delirrad; Investigation: Rasool Entezarmahdi; Writing review \& editing: All authors.

\section{Conflict of interest}

The authors declared no conflict of interest.

\section{Acknowledgements}

The authors would like to acknowledge the Deputy of Health, Urmia Medical Sciences University for providing information.

\section{References}

[1] Kadivar MR, Aramesh K, Sharifi B., Asadafrooz S. [The prevalence and causes of mortality in Fars Province, Iran in 2001 (Persian)]. J Hormozgan Univ Med Sci. 2006; 10(1):47-55. https:// www.sid.ir/fa/journal/ViewPaper.aspx?id=67895

[2] Sasanipour M. [The coverage of adult mortality using Brass growth balance in 1385: Markazi and Boushehr Provinces (Persian)]. Iran J Offic Statis Stud. 2012; 23(2):243-54. http:// ijoss.srtc.ac.ir/article-1-47-fa.html

[3] Pilehvar AA, Feizabadi R, Afra H. [Effective etiology and geographic distribution of deaths in North Khorasan Province (Persian)]. J Geogr Regio Dev. 2014; 10(19): 119-41. https:// www.sid.ir/fa/journal/ViewPaper.aspx?id=195059

[4] Majidi M, Ghaemi S, Javaezi M, Delirrad M. [A study on human mortalities and death registration system in West
Azerbaijan Province of Iran (Persian)]. Iran J Foren Med (SJFM). 2016; 22(3):193-202. http://sjfm.ir/browse.php?a id $=841 \&$ sid $=1 \&$ slc $\_l a n g=$ fa

[5] Nejadrahim R, Sahranavard M, Aminizadeh A, Delirrad $M$. Snake envenomation in North-West Iran: A three-year clinical study. Int J Med Toxicol Legal Med. 2019; 9(1):31-8. [DOI:10.22037/ijmtfm.v9i1(Winter).24072]

[6] Statistical Center of Iran (SCI). Selected findings of the 2016 (1395) national population and housing census. Tehran: Statistical Center of Iran. Available from: Last accessed: September 16 2019. Aug. 2018. 51 p. https://www.amar.org.ir/ english/Latest-Releases-Page/ID/5689/Selected-Findingsof-the-2016-National-Population-and-Housing-Census

[7] World Health Organization (WHO). International Statistical Classification (ISD) of Diseases and Related Health Problems; $10^{\text {th }}$ edition. Geneva: WHO; 2008. Available from: https://icd. who.int/browse10/2008/en.

[8] National Organization for Civil Registration. [Vital events statistics, registered birth in the whole country according to provincial separation in 1395 (2016-2017) (Persian)]. Available from https://www.sabteahval.ir/Upload/Modules/Contents/asset99/95-1.pdf.

[9] National Organization for Civil Registration. [Vital events statistics, recorded death in the whole country according to provincial separation in 1395 (2016-2017) (Persian)]. Available from https://www.sabteahval.ir/Upload/Modules/Contents/asset $99 / \mathrm{f}-2$.pdf.

[10] Urmia University of Medical Sciences. [Statistical yearbook of 1395 (2016-2017). P. 24 (Persian)]. Available from: https:/ sit.umsu.ac.ir $/$ index.aspx?siteid=30\&fkeyid=\&siteid=30\&pa geid $=22136$

[11] Office of Statistics, Demographic information \& Immigration. Population Statistics Yearbook 1390 (2011-2012), Tehran. Iranian National Organization for Civil Registration; 2012. 522 pp. Last accessed: 16 September 2019. Available from: http://www.sabteahval.ir/upload/modules/contents/asset90/death.pdf

[12] National Organization for Civil Registration. Vital events statistics, recorded death in the whole country according to provincial separation in 1390 (2011-2012) (Persian)]. Available from: http://www.sabteahval.ir/Upload/Modules/Contents/asset90/death.pdf.

[13] Ferdosi M, Mohammadi-Sefiddashti F, Aghdak P, Moradi R, Mofid M, Rejalian F, et al. Death portrait of Isfahan Province in years 2007-2011. Int J Prev Med. 2016; 7:96. [DOI:10.4103/2008-7802.187250] [PMID] [PMCID]

[14] Faghihi F, Jafari N, Akbarisari A, Nedjat S, Milani MH. Trend of mortality rate and causes of death in Qazvin Province. Iran J Foren Med (SJFM). 2015; 21(1):35-42.

[15] Kazemi T, Sharifzadeh G. Study of causes of death in population under supervision of Birjand University of Medical Sciences. J Birjand Univf Med Sci. 2003; 10(2):9-15. http:// journal.bums.ac.ir / browse.php?a_id $=187 \&$ sid $=1 \&$ \&lc lang $=\mathrm{fa} \& \mathrm{ftxt}=0$

[16] Azizi A, Abdoli GR. [Mortality rates in Kermanshah Province in 2000 (Persian)]. J Kermanshah Univ Med Sci. 2003; 7(3):10-7. https://www.sid.ir/fa/journal/ViewPaper. aspx?id $=6322$ 
[17] Amani F, Kazemnejad A. Changing pattern of mortality trends in Iran, South, South-West Asia and World, 1970-2010. Iran J Public Health. 2010; 39(3):20-6. [PMID] [PMCID]

[18] Alizadeh M, Momene-Tayefe M, Toudeh-Fallah M, Amirkhosravi M, Khatibi A, Barani H, et al. [Population Statistics Yearbook of 1395 (2016-2017). Office of Statistics, Demographic information \& Immigration (Persian)]. National Organization for Civil Registration of Iran; 2017. p. 650. https:/ / www.sabteahval.ir/DeskTopModules/Magazines/showattachment.aspx?id=3307\&mId=49823

[19] World Health Organization (WHO). International Classification of Diseases (ICD) 11: The global standard for diagnostic health information. Available from: https://icd.who.int/en/ 